\title{
Economic Fluctuations and Urban-rural Differences in Educational Inequalities in Mortality in Three Baltic Countries and Finland in 2000- 2015: A Register-based Study
}

Mall Leinsalu ( $\square$ mall.leinsalu@sh.se)

Sodertorns hogskola https://orcid.org/0000-0003-4453-4760

Aleksei Baburin

Tervise Arengu Instituut

Domantas Jasilionis

Max Planck Institute for Demographic Research

Juris Krumins

University of Latvia

Pekka Martikainen

University of Helsinki

Andrew Stickley

Sodertorns hogskola

Short report

Keywords: Educational inequalities, Macroeconomic changes, Mortality, Urban-rural differences

Posted Date: July 23rd, 2020

DOI: https://doi.org/10.21203/rs.3.rs-45703/v1

License: (c) (i) This work is licensed under a Creative Commons Attribution 4.0 International License. Read Full License 


\section{Abstract}

We examined urban-rural differences in educational inequalities in mortality in three Baltic countries and Finland in the context of macroeconomic changes. Educational inequalities among 30-74 year olds were examined in 2000-2003, 2004-2007, 2008-2011 and 2012-2015 using census-linked longitudinal mortality data. We estimated age-standardized mortality rates and the relative and slope index of inequality. Overall mortality rates were larger in rural areas except among Finnish women. Relative educational inequalities in mortality were often larger in urban areas among men but in rural areas among women. Absolute inequalities were mostly larger in rural areas. Between 2000-2003 and 2012-2015 relative inequalities increased in most countries while absolute inequalities decreased except in Lithuania. In the Baltic countries the changes in both relative and absolute inequalities were more favourable in urban areas; in Finland they were more favourable in rural areas. The overall pattern changed during the reccessionary period between 2004-2007 and 2008-2011 when relative inequalities often diminished or the increase slowed, while the decrease in absolute inequalities accelerated with larger improvements observed in urban areas. Despite substantial progress in reducing overall mortality rates in both urban and rural areas in all countries, low educated men and women in rural areas in the Baltic countries are becoming increasingly disadvantaged in terms of mortality reduction.

\section{Introduction}

Educational inequalities in mortality persist in Europe although in most countries mortality rates have also declined rapidly among the low educated [1]. Despite extensive research on educational inequalities in mortality, very little is known about how educational inequalities in mortality differ between urban and rural residents within countries. An urban-rural mortality gap has developed in many countries over recent decades, mostly because of larger mortality reductions in urban areas [2]. Socioeconomic deprivation, more limited access to health care and unhealthy lifestyles have been related to the rural mortality disadvantage [2]. Social determinants of health are linked to wider macrolevel processes [3] that may affect urban and rural areas differently. Strong economic growth in Europe between 2000 and 2008 was more pronounced in urban areas with capital metro regions experiencing the highest per capita GDP growth rates, although they were also the regions most negatively affected by the recession after 2008 , linked to sharper contractions in employment [4]. Some earlier studies found that overall mortality rises when the economy is expanding and falls during recessions, however there is also some evidence that this pro-cyclical association may be related to urban areas only [5].

As the impact of economic fluctuations on educational inequalities in mortality in urban and rural areas has not yet been studied, the aim of the current study was to examine urban-rural differences in educational inequalities in mortality in three Baltic countries and Finland in relation to large-scale macroeconomic changes between 2000 and 2015. The Baltic countries experienced rapid economic growth and low unemployment until 2008 and a deep recession with unemployment tripling afterwards; in Finland the changes were less extreme (Supplementary Fig. 1).

\section{Methods}

Data for Estonia, Latvia and Lithuania come from longitudinal mortality follow-up studies of population censuses in 2000/01 and 2011 where all permanent residents who participated in the census were followed from the census date until the date of death or emigration, or until the end of the follow-up period.Death data were linked from national mortality registries with $95-98 \%$ of deaths being successfully matched to census records. All data linkages were performed by National Statistical Offices. Data for Finland were obtained from the longitudinal register-based population data file of Statistics Finland covering the total population. Data were organized into four sub-periodsrepresenting moderate economic growth (2000-2003), economic expansion (2004-2007), recession (2008-2011), and economic recovery (2012-2015). Sociodemographic characteristics are census based and were coded using a common study protocol. Urban-rural residence was defined using national administrative classifications. The size of the urban population was larger in Finland (Supplementary Table 1). Educational level was categorized as low, referring to the International Standard Classification of Education 2011 categories 0-2, middle(3-4), and high(5-8).Less than 1\% of the values were missing for education and these cases were omitted from the analyses that included approximately 889 thousand deaths and 104 million person years in the 30-74 age group. The percentage of low educated was larger in rural areas in all countries but was less marked in Finland (Supplementary Table 1).

Age-standardized mortality rates (ASMRs) per 100000 person years were calculated using 5-year age groups and the 1976 European Standard Population. Educational inequalities in mortality were assessed using the relative index of inequality (RII) and the slope index of inequality (SII) [6]. The $\mathrm{RII}$ is a regression-based measure that adjusts the relative position of each educational group to its share in the population thus taking into account differences in the educational distribution between populations and between urban and rural areas. The SII measures absolute mortality rate differences between the lowest and highest end of the educational hierarchy. The SIls were calculated from the RIls and overall ASMRs using the formula SII = $2 * A S M R *(R I I-1) /(R \|+1)$.

Statistical analyses were performed using SPSS Statistics for Windows, version 26.0 (IBM Corp. 2019) and STATA 14.2 (Stata Corp., College Station, Texas, USA).

\section{Results}

The ASMRs were higher in rural areas in all countries except for women in Finland where they were about the same as in urban areas (Table 1 and 2). Between 2000-2003 and 2012-2015, the ASMRs decreased in all countries with a slightly larger decline observed in urban areas, excepting Latvian men and Finnish women where ASMRs declined somewhat more in rural areas. Although the ASMRs mostly decreased or remained the same between 
2000-2003 and 2004-2007, they grew in Lithuania with a larger increase occurring in rural areas. From 2004-2007 to 2008-2011, the ASMR decline accelerated in nearly all countries and was larger in urban areas. From 2008-2011 to 2012-2015 the ASMRs continued to fall with a larger decline seen more often in rural areas.

In all settings, higher educated men and women had lower mortality compared to the lower educated (Table 1 and 2 ). Among men the RIls were larger in urban areas except in Estonia in 2008-2015 and in Lithuania in 2008-2011. Among women the Rlls were larger in rural areas except in Finland in 2008-2015, in Estonia in 2000-2003 and Latvia in 2000-2007. Between 2000-2003 and 2012-2015 the Rlls increased in most countries in both urban and rural areas excepting rural men in Finland and urban women in Estonia. The overall RII increase was particularly large in Latvia and Lithuania (especially in rural areas) but was also substantial among rural men and women in Estonia and among urban women in Finland.

Between 2000-2003 and 2004-2007, in the Baltic countries, the Rlls increased more/decreased less in rural areas except among Latvian men. In Finland the RII increase was larger in urban areas. From 2004-2007 to 2008-2011 the RIls increase slowed or the RIls decreased except among women in Latvia and among rural men in Lithuania and Finland; the change was generally more favourable in urban areas. In most countries, except among rural men in Finland and Lithuania and among rural women in Latvia, the largest RII increase occurred between 2008-2011 and 2012-2015; the RII increase was larger in urban areas except among men in Latvia and among women in Estonia and Lithuania where it was larger in rural areas.

Absolute educational inequalities (SIls)in mortality were larger in rural areas except among Finnish men and women (in 2012-2015 only). From 20002003 to 2012-2015 the Slls generally decreased, or remained about the same in most countries except in Lithuania where they increased. In the Baltic countries the overall SII decline was larger or the increase was smaller (in Lithuania) in urban areas, except among Latvian men. In Finland, a larger decrease was observed in rural areas. In nearly all countries the SIl decline accelerated between 2004-2007 and 2008-2011, especially in urban areas.

\section{Discussion}

The censuses in the Baltic countries combined traditional survey-based enumeration and register-based enumeration. The share of the population enumerated using only survey-based enumeration varied from $91 \%$ in Latvia to $98 \%$ in Estonia [7]. The register-based data did not cover information about educational level and were thus excluded from the analysis. A sensitivity analysis performed for Latvia showed that by excluding register-based records we slightly underestimated overall mortality but the effect on changes between the periods was minimal (Supplementary Table 2). Although we cannot exclude the possibility that the effect differed by educational level or urban-rural residence, we believe that this bias did not have any major effect on our conclusions related to the mortality changes in Latvia.

As the same determinants often undepin educational inequalities in mortality and urban-rural mortality differences [3]they mayact to amplify each other In accordance with previous research [2], the overall mortality rates were larger in rural areas except among Finnish women. Differences between urban and rural areas in educational distribution and socioeconomic deprivation i.e. unemployment, poverty and social exclusion [8]may possibly explain part of the urban-rural mortality gap. The risk of impoverishment and becoming unemployed is closely connected to macroeconomic changes. In the Baltic countries, the economic consequences of the recession were more pronounced in the cities where the unemployment rate increased by four times [8]. In Finland, the economic consequences were smaller and did not differ substantially between urban and rural areas. Overall mortality rates were responsive to macroeconomic changes; between 2004-2007 and 2008-2011 the mortality decline accelerated in all countries in line with a pro-cyclical mortality pattern. The mortality decline during the recession was somewhat larger in urban areas, thus supporting the findings of an earlier study [5].

Large educational inequalities in mortality were found in both urban and rural areas. Among men the relative inequalities were often larger in urban areas but among women they were larger in rural areas. Although educational inequalities in mortality can reflect differences in employment opportunities and poverty risk as well as in healthcare access and health behaviours [3] in both urban and rural areas, we can only speculate why inequalities in mortality were larger among urban men but among rural women. Differences in the diffusion of the tobacco epidemic might help explain this urban-rural gender gap particularly in the Baltic countries. Namely, earlier research from Estonia showed that the reversal of the educational gradient in smoking was considerably delayed among women compared with menand that women in urban areas were also more likely to have everinitiated smoking compared to in rural areas [9],which may have contributed to compressing inequalities in mortality among urban women.

Between 2000-2003 and 2012-2015 relative inequalities in mortality increased in nearly all countries while absolute inequalities mostly decreased. However, during the recession, relative inequalities in mortality decreased or the increase slowed while the decrease in absolute inequalities accelerated. These results accord with an earlier study from Spain showing that all-cause mortality decreased more during the recession, especially in socioeconomically disadvantaged groups [10]. The larger contraction of the economy in urban regions during the recession [8] might therefore explain the larger urban reduction in educational inequalities in mortality. Although relative inequalities in mortality increased in nearly all settings during the economic recovery period, the overall changes in both relative and absolute inequalities between 2000-2003 and 2012-2015 were more favourable in urban areas in the Baltic countries but in rural areas in Finland.

Despite substantial progress in reducing overall mortality rates in both urban and rural areas in all countries, low educated men and women in rural areas in the Baltic countries are becoming increasingly disadvantaged in terms of their mortality reduction.

\section{Declarations}

\section{Ethics approval and consent to participate}


Not applicable.

\section{Consent for publication}

Not applicable.

\section{Availability of data and materials}

The data that support the findings of this study are available from National Statistical Offices, i.e. Statistics Estonia, Statistics Lithuania, Central Statistical Bureau of Latvia and Statistics Finland but restrictions apply to the availability of these data, which were used under license for the current study, and so are not publicly available. Data are however available from the authors upon reasonable request and with permission of data providers

\section{Competing interests}

The authors declare that they have no competing interests.

\section{Funding}

This study was financed by RiksbankensJubileumsfond - The Swedish Foundation for Humanities and Social Sciences (grant P15-0520:1). The work by DJ has been supported by the Max Planck Society within the framework of the project "On the edge of societies: New vulnerable populations, emerging challenges for social policies and future demands for social innovation. The experience of the Baltic Sea States" (2016-2021). PM is supported by the Academy of Finland. JK is supported by the Latvian National Research Project "Demomig".

\section{Authors' contributions}

ML conceptualized the study, contributed to the data preparation, analysed the data and wrote the first and final drafts of the paper. AS helped in the formulation of core ideas, contributed to data interpretation and critically reviewed the manuscript. AB, JD, JK and PM provided data for their countries, discussed the core ideas, contributed to data interpretation and critically reviewed the manuscript. All authors approved the final version.

\section{Acknowledgements}

Not applicable.

\section{References}

1.Mackenbach JP, Rubio Valverde J, Bopp M, et al. Progress against inequalities in mortality: register-based study of 15 European countries between 1990 and 2015. Eur J Epidemiol. 2019;34:1131-42.

2.Singh GK, Siahpush M. Widening rural-urban disparities in all-cause mortality and mortality from major causes of death in the USA, 1969-2009. J Urban Health. 2014;91:272-92.

3.Marmot M, Allen J, Bell R, et al. WHO European review of social determinants of health and the health divide. Lancet 2012;380:1011-29.

4.Dijkstra L, Garcilazo E, McCann P. The effects of the global financial crisis on European regions and cities. JEconGeogr. 2015;15:935-49.

5.Sameem S, Sylwester K. The business cycle and mortality: urban versus rural counties. Soc Sci Med. 2017;175:28-35.

6.Mackenbach JP, Kunst AE. Measuring the magnitude of socio-economic inequalities in health: an overview of available measures illustrated with two examples from Europe. Soc Sci Med. 1997;44:757-71.

7.Statistical Office of Estonia, Central Statistical Bureau of Latvia, Statistics Lithuania. 2011 Population and housing censuses in Estonia, Latvia and Lithuania. 2015. https://osp.stat.gov.It/services-portlet/pub-edition-file?id=19698. Accessed 10 May 2020.

8.EC. Eurostat database, 2020. https://ec.europa.eu/eurostat/data/database. Accessed 10 May 2020.

9.Leinsalu $M$, Tekkel M, Kunst AE. Social determinants of ever initiating smoking differ from those of quitting: a cross-sectional study in Estonia. Eur $J$ Public Health. 2007;17:572-8.

10.Regidor E, Vallejo F, Granados JAT, Viciana-Fernandez FJ, de la Fuente L, Barrio G. Mortality decrease according to socioeconomic groups during the economic crisis in Spain: a cohort study of 36 million people. Lancet. 2016;388:2642-52.

\section{Tables}

Table 1 Age-standardized mortality rates and educational inequalities in mortality in urban and rural areas in 2000-2015 among men in the 30-74 age group 


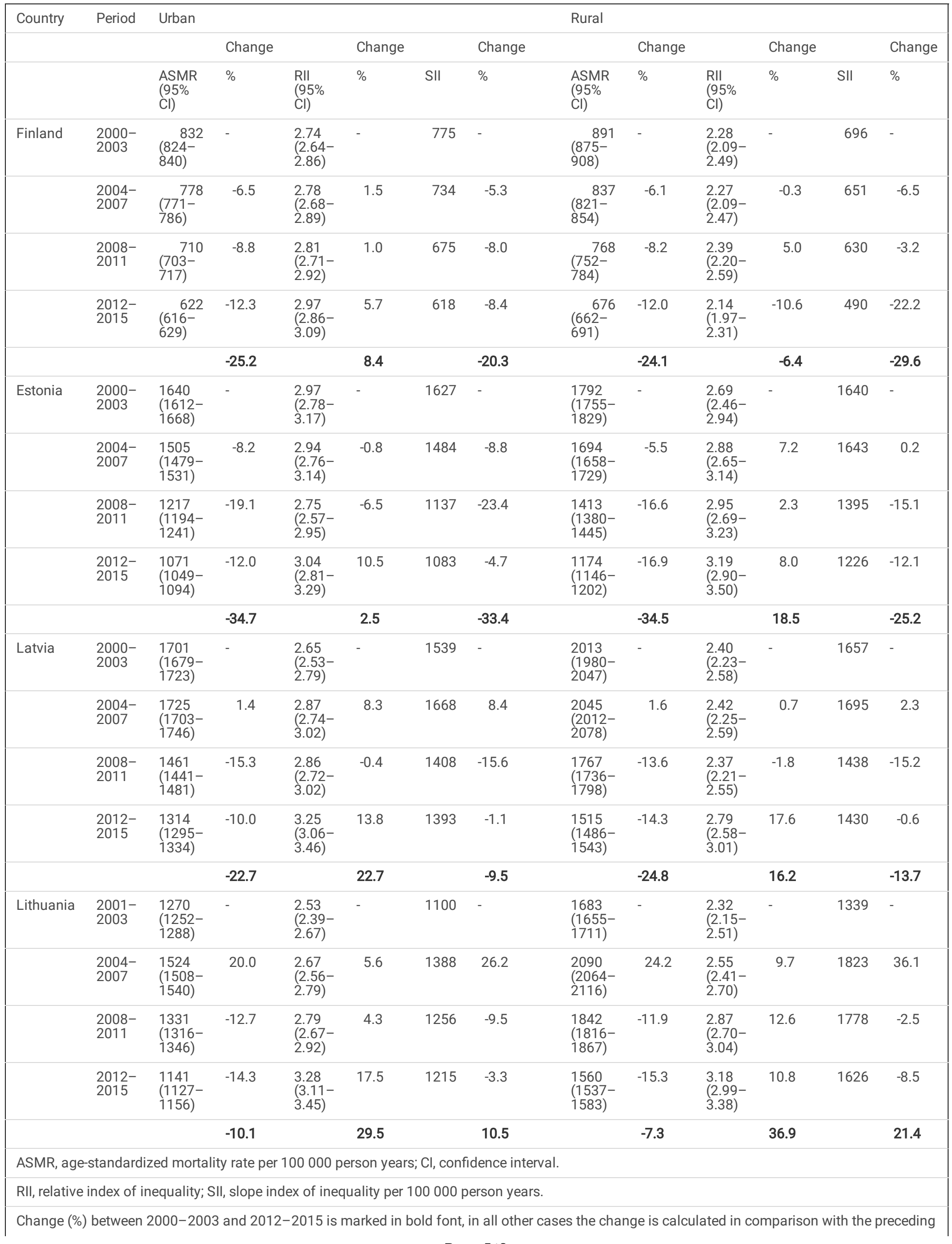

Page 5/8 
period.

Table 2 Age-standardized mortality rates and educational inequalities in mortality in urban and rural areas in 2000-2015 among women in the 30-74 age group 


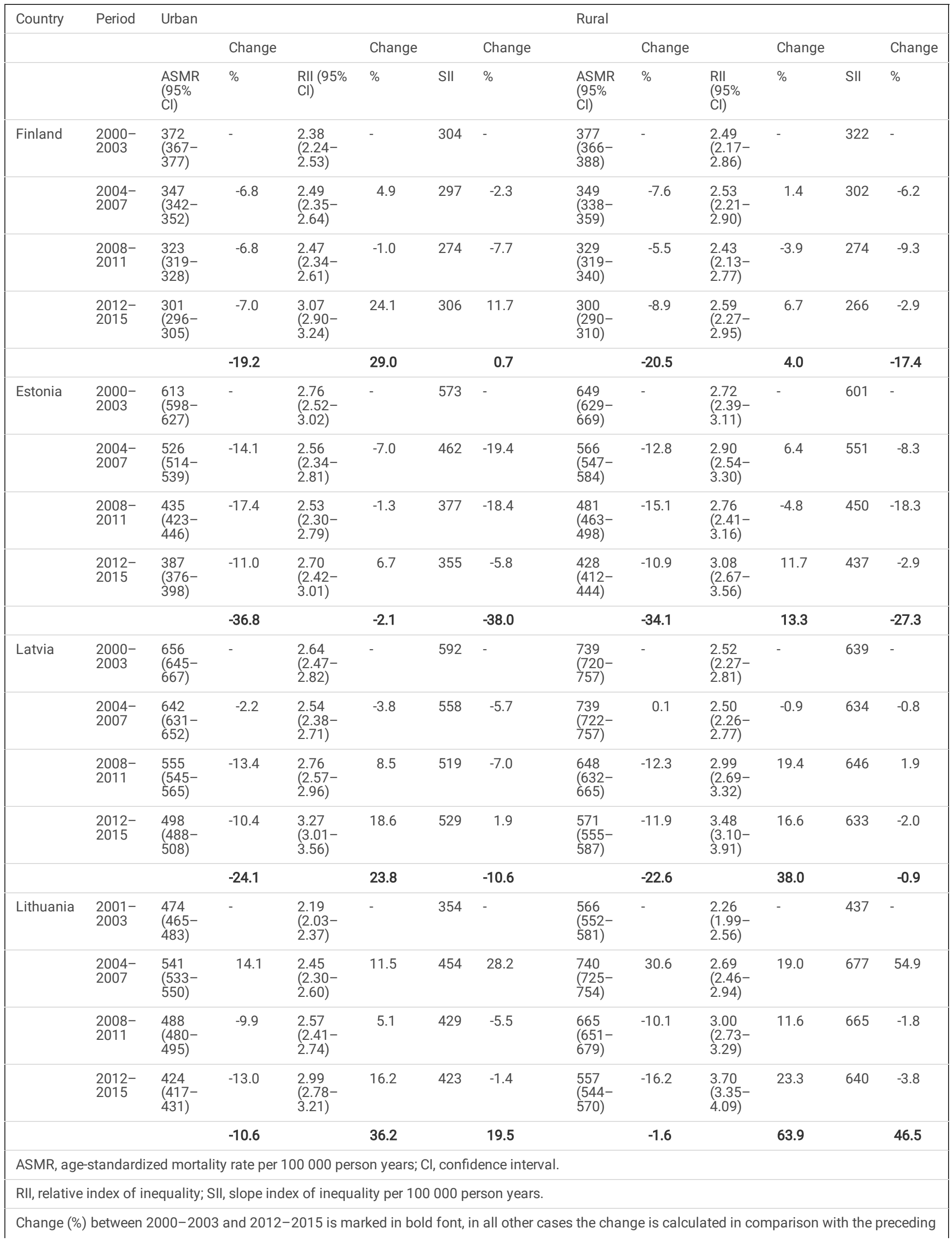

Page 7/8 


\section{Supplementary Files}

This is a list of supplementary files associated with this preprint. Click to download.

- UrbanruralsupplementarylJEH12.07.2020.docx 